\title{
Three-dimensional printing titanium ribs for complex reconstruction after extensive posterolateral chest wall resection in lung cancer
}

\author{
Lei Wang, MD, ${ }^{\mathrm{a}}$ Tiesheng Cao, MD, ${ }^{\mathrm{b}}$ Xiaofei Li, MD, ${ }^{\mathrm{a}}$ and Lijun Huang, MD, ${ }^{\mathrm{a}}$ Xi' an, China
}

\footnotetext{
From the Departments of ${ }^{\mathrm{a}}$ Thoracic Surgery and ${ }^{\mathrm{b}}$ Diagnostic Ultrasound, Tangdu Hospital, the Fourth Military Medical University, Xi'an, China.

This work was supported by the Basic Research Innovation Fund and Young Talent Fund of Tangdu Hospital, the Fourth Military Medical University, Xi' an, PR China.

Disclosures: Authors have nothing to disclose with regard to commercial support.

Received for publication Dec 1, 2015; revisions received Feb 14, 2016; accepted for publication Feb 21, 2016; available ahead of print April 1, 2016.

Address for reprints: Lijun Huang, MD, Department of Thoracic Surgery, Tangdu Hospital, Fourth Military Medical University, 577 Xinsi Rd, Xi'an, People's Republic of China (E-mail: tuodi1986@126.com). J Thorac Cardiovasc Surg 2016;152:e5-7 $0022-5223 / \$ 36.00$

Copyright (C) 2016 by The American Association for Thoracic Surgery http://dx.doi.org/10.1016/j.jtcvs.2016.02.064
}

Large chest wall resection is essential for T3 non-small cell lung cancer with invasion of the chest wall. Skeletal reconstruction using moldable titanium plates, bars, and meshes is the common option to prevent the frequent complications associated with this procedure. ${ }^{1}$ Threedimensional printing (3DP) titanium implants have offered a valid option with perfect anatomic fitting and an almost infinite variety of designs. ${ }^{2}$ Herein, we present a case of chest wall reconstruction using the 3DP technique.
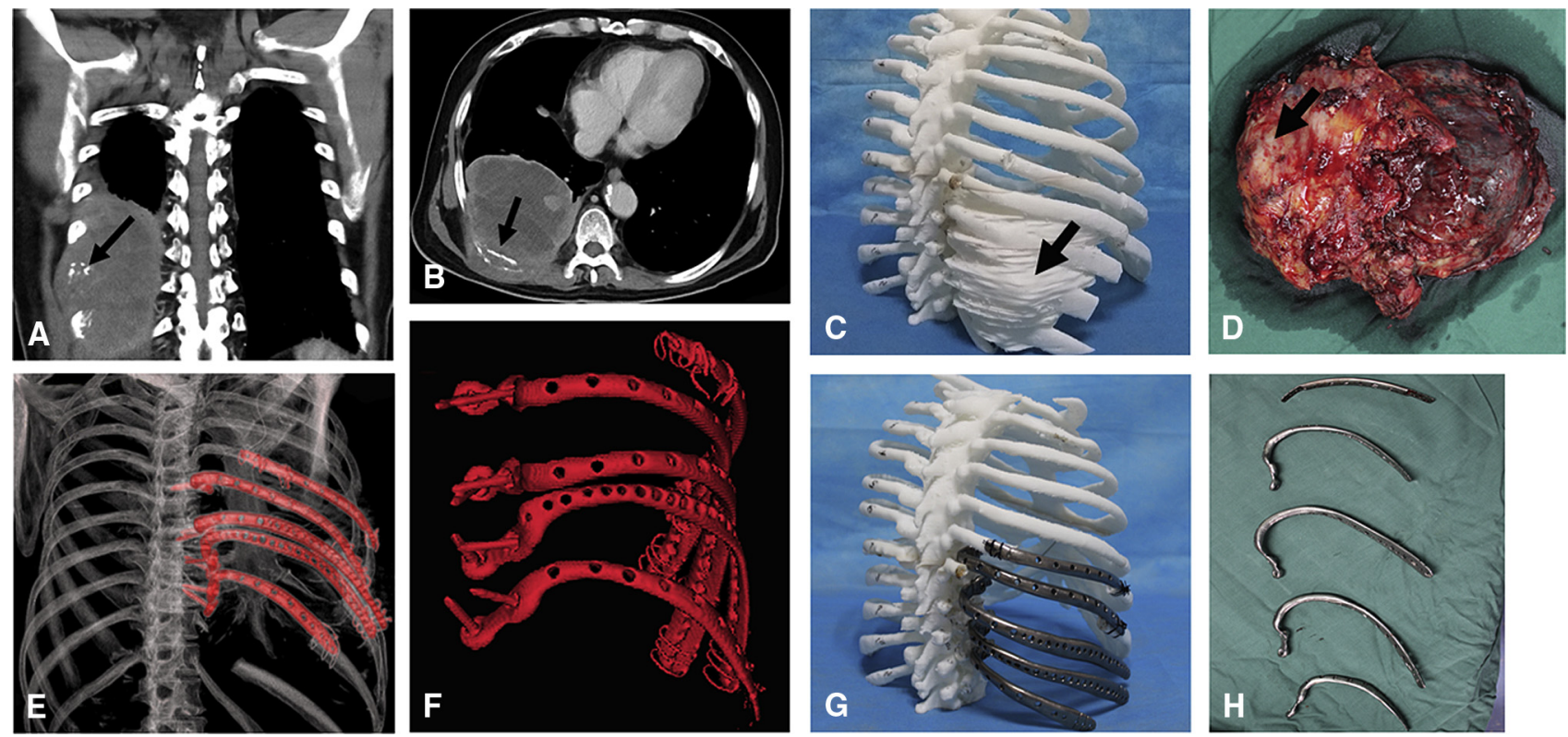

FIGURE 1. The chest computed tomography scans using (A) coronal and (B) horizontal scanning. C, 3-dimensional printing thoracic model and (D) the en bloc excised tumor specimen. The black arrow points out the tumor invasion with the ribs. E and F, The 3-dimensional computed tomography scan after the reconstruction using titanium ribs. $\mathrm{G}$, The titanium ribs were fixed on the thoracic model before surgery. $\mathrm{H}$, The 5 titanium ribs. 

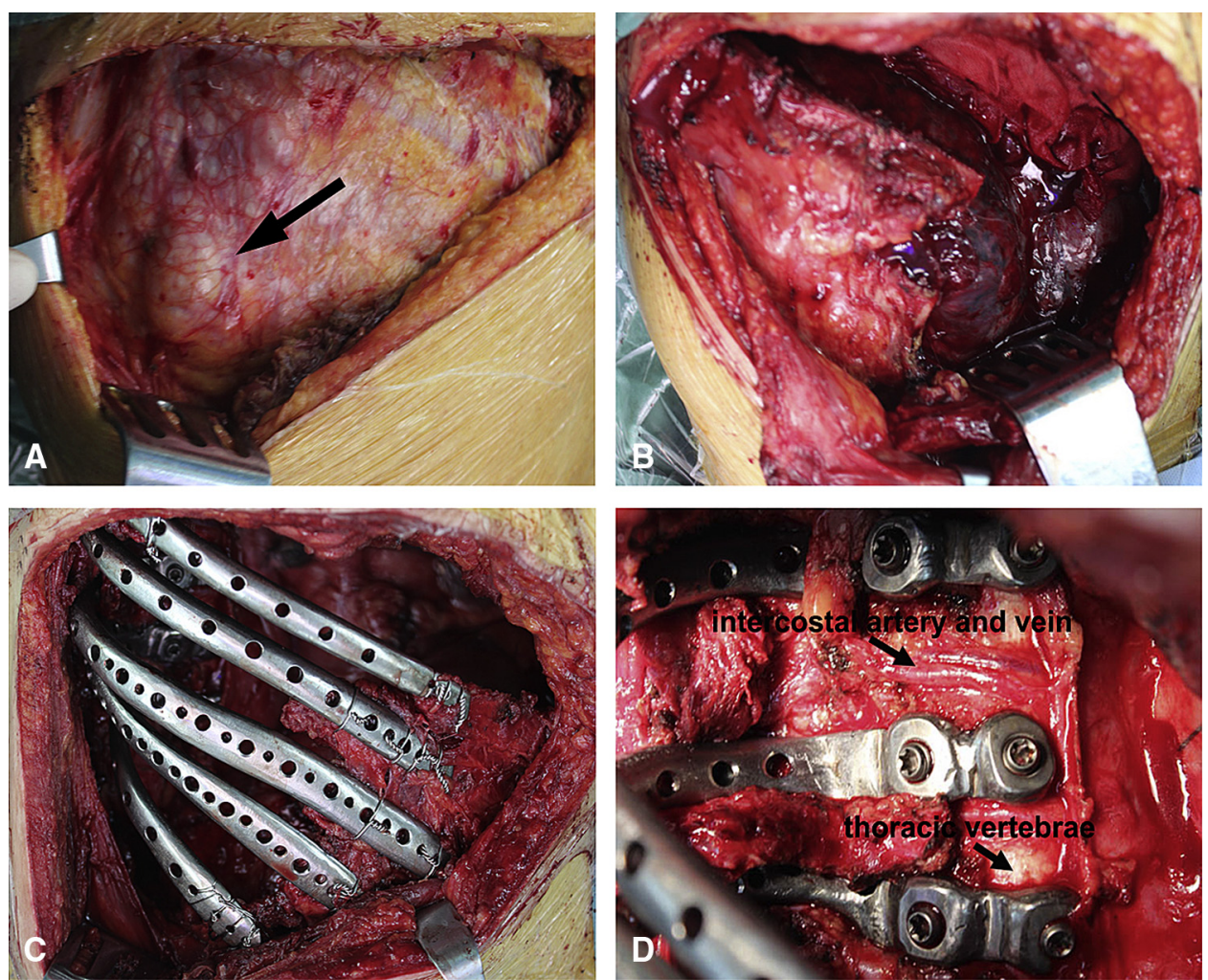

FIGURE 2. A, The tumor had invaded the chest wall, from the sixth to 10th ribs (black arrow). B, A radical complete (R0) en bloc resection of the inferior lobe of the right lung to a $15 \times 15 \mathrm{~cm}$ section of the posterior chest wall, from the sixth to 10th ribs, was performed. C, The 3-dimensional printing titanium ribs were implanted into the chest wall and bound with the residue ribs via steel wiring. $\mathrm{D}$, The 3-dimensional printing titanium ribs were anchored to the thoracic vertebra by using angle-stable, self-locking nails.

mass on the right inferior lobe of the lung, with invasion of posterior chest wall, from the sixth to 10th ribs (Figure 1, $A$ and $B$ ). The whole body positron emission tomography $\mathrm{CT}$ and bone scintigraphic imaging presented a localized disease without any distant metastasis in other organs. A high-accuracy 3-dimensional (3D) CT scan with a slice thickness of $1.25 \mathrm{~mm}$ was performed to obtain preoperative images of the thorax, and then the images were exported in DI-COM format to 3D-DOCTOR imaging software (Able Software Corp, Lexington, Mass). Polylactic acid materials were used to create the 3DP thoracic model (Figure 1,C) on which the resection margin was estimated at a minimum distance of $2 \mathrm{~cm}$ beyond the cancer (Figure 1,D). The length of each 3DP titanium rib was beyond the prospective resection margin of 3 to $4 \mathrm{~cm}$, which made enough room for unpredictable situations (Figure 1, $E$ and $F$ ). An EOS M280 3DP machine (EOS GmbH, Krailling, Germany) subsequently produced these implants from surgical-grade titanium alloy with a whole weight of $275 \mathrm{~g}$ (Figure $1, G$ and $H$ ). The 3DP process cost about $\$ 300$ for the thoracic model and $\$ 13,800$ for the titanium ribs. Two weeks were spent on this procedure, including 1 week of designing and evaluating, 26 hours of printing, and 4 days of postsurgical grade processing.

The patient underwent a radical complete en bloc resection of the inferior lobe of the right lung to a $15 \times 15 \mathrm{~cm}$ section of the posterior chest wall, from the sixth to 10th ribs (Figure 2, $A$ and $B$ ). The disease-free resection margins were established during operation on the basis of frozen tissue section analysis. An additional resection would be adopted if a positive margin was found. The titanium ribs were bound with the residue ribs via steel wires, and the other ends were anchored into the thoracic vertebra using angle-stable, self-locking nails (Figure 2, $C$ and $D$ ). The 2 self-locking nails could simultaneously anchor the titanium ribs to the thoracic vertebra at a certain angle, and this structure ensures the stability of implants to the greatest extent. A dual mesh patch and latissimus dorsi myocutaneous pedicled flap were fixed on the inner and outer surface of the titanium ribs, respectively. Histopathology showed a grade II squamous cell carcinoma, and the TNM stage was classified as T3 N1 M0 (stage IIB). The patient was discharged home 15 days after surgery and the chest CT scan showed a stable reconstruction, with 
preservation of thoracic morphology and excellent cosmetic results.

\section{COMMENT}

Biomimetic reconstructions are expected to offer better function and cosmetic results after extensive chest wall resection. ${ }^{3}$ Especially for the posterolateral chest wall, no skeletal autograft implant can be used for reconstruction of this region. ${ }^{4}$ The 3DP technique allows users to rapidly convert digital 3D models into a perfect titanium implant. Some competitive advantages include that 3D computer-assisted design eliminates the need to shape, cut, or contour the implant and this procedure may produce a perfect anatomic fit. $^{2}$ Moreover, the $3 \mathrm{DP}$ technique can provide an almost infinite variety of designs of implants according to the individual demands of each patient, including rare or uncommon cases. ${ }^{5}$

The cost and production time of 3DP titanium prostheses are considerable and notable. The production time was relative for cancer progression or metastasis; thus, this technique should be restrained to highly aggressive cancers. Furthermore, it must be considered in advance so that the resection extent may be expand beyond the operation plan, which may result in inconformity between the 3DP prosthesis and the chest wall defect. A segmental link device can be added to the prosthesis to easily adjust the length of the implant. Traditional implants, such as titanium plates, bars, and meshes, should be prepared as an alternative. With 3DP implants being accepted on a larger scale, it is important to establish a thorough regulatory practice and avenue for this technique that involves the materials, physicochemical property, biocompatibility, processing methods, and other aspects.

\section{References}

1. Weyant MJ, Bains MS, Venkatraman E, Downey RJ, Park BJ, Flores RM, et al. Results of chest wall resection and reconstruction with and without rigid prosthesis. Ann Thorac Surg. 2006;81:279-85.

2. Aranda JL, Jiménez MF, Rodríguez M, Varela G. Tridimensional titanium-printed custom-made prosthesis for sternocostal reconstruction. Eur J Cardiothorac Surg. 2015;48:e92-4.

3. Berthet JP, Canaud L, D'Annoville T, Alric P, Marty-Ane CH. Titanium plates and dualmesh: a modern combination for reconstructing very large chest wall defects. Ann Thorac Surg. 2011;91:1709-16.

4. Berthet JP, D'Annoville T, Canaud L, Marty-Ané CH. Use of the titanium vertical ribs osteosynthesis system for reconstruction of large posterolateral chest wall defect in lung cancer. Int Cardiovasc Thorac Surg. 2011;13: 223-5.

5. Malik HH, Darwood AR, Shaunak S, Kulatilake P, El-Hilly AA, Mulki O Three-dimensional printing in surgery: a review of current surgical applications. J Surg Res. 2015;199:512-22. 